\title{
Dynamic Modelling of Multitubular Catalytic Reactors
}

\begin{abstract}
Andrzej Stankiewicz and Gerhart Eigenberger*
This paper presents a study on modelling and simulation of transient operational characteristics in multitubular fixed-bed reactors. The dynamic model of the reactor is based on a "porous body" approach which regards the intertubular space as a pseudo-homogeneous environment. Such an approach permits to take into account most factors in the geometrical design of the unit and thus to study the influence of various shell-side geometrical and operational parameters on the reactor behaviour. Based on the model, the dynamic responses of the two most common industrial reactor designs, i.e. the parallel flow unit with distributing plates and the crossflow reactor with disk-and-doughnut baffles have been investigated and compared. In addition, some problems of correct space discretization and use of time-dependent regridding procedures, are discussed.
\end{abstract}

\section{Introduction}

In their previous papers $[1-4]$, both authors considered various aspects of multitubular reactor operation. Stankiewicz [4] proposed a mathematical model of the cocurrent multitubular unit operating under steady-state conditions. There, it was found that some of the geometrical (design) factors, such as tube diameter/tube pitch ratio or tube-to-baffle clearances, can exert a strong influence on the operational characteristics of the unit.

The aim of this study was to create a reliable and user-friendly mathematical model for simulation of the dynamic behaviour of multitubular catalytic reactor systems. The numerical package based on the model is expected to be incorporated into the DIVA programme $[5,6]$, a tool for the dynamic simulation of process plants.

The hitherto developed models of fixed-bed reactors applied either single-tube units with uniform conditions of heat removal along the tube or idealized rectangular tube bundles with no leakage by-pass flows via the tube-to-baffle clearances and constant coolant velocity throughout the intertubular space [7-9]. In contrast, the present model should allow to include the details of the shell-side phenomena in the consideration, and thus to investigate the influence of the geometrical design of intertubular space on the dynamic behaviour of the reactor.

\section{The Model}

The main assumption and a novel feature of the present model is a "porous body" approach, which implies that the entire intertubular space is regarded as a pseudo-homogeneous environment with coolant flow in radial and axial directions, taking local variations of heat transfer from the reactor tubes into account.

* Dr. A. Stankiewicz, Industrial Chemistry Research Institute, Rydygiera 8, 01-793 Warszawa, Poland, present address: DSM Research, P.O Box 18, 6160 MD Geleen, The Netherlands, and Prof. Dr.-Ing. G. Eigenberger, Institute of Chemical Engineering, University of Stuttgart, Bocblinger Str. 72, D-7000 Stuttgart 1.
All the mass and heat balances on the shell and tube sides are based on the unit volume of the shell. Therefore, it is necessary to introduce several parameters which would relate certain factors in the reactor geometry to unit volume of the shell, namely: ${ }^{1)}$

$a_{\mathrm{ex}}^{v}=\frac{\text { external area of tube walls }}{\text { unit volume of shell (incl. tubes) }}$,

$a_{\mathrm{in}}^{v}=\frac{\text { internal area of tube walls }}{\text { unit volume of shell }}$

$a_{\mathrm{t}}=\frac{\text { inner cross-sectional area of tubes }}{\text { unit cross-sectional area of shell }}=$

$$
=\frac{\text { internal volume of tubes }}{\text { unit volume of shell }} \text {, }
$$

$\varepsilon_{\mathrm{c}}^{v}=$ shell voidage $=\frac{\text { volume of coolant }}{\text { unit volume of shell }}$,

$\varepsilon_{\mathrm{w}}^{v}=\frac{\text { volume of tube walls }}{\text { unit volume of shell }}$,

$\varepsilon_{\mathrm{f}}^{\nu}=\frac{\text { volume of reacting gas }}{\text { unit volume of shell }}$

It can be seen easily that

$\varepsilon_{\mathrm{f}}^{v}=\varepsilon a_{\mathrm{t}}$.

where $\varepsilon$ is the porosity of packed bed.

1) List of symbols at the end of the paper. 
Definition of such parameters leads to the formulation of the general model equations as follows:

Coolant heat balance:

$\varrho_{\mathrm{c}} c_{\mathrm{pc}} \varepsilon_{\mathrm{c}}^{v}\left[\frac{\partial T_{\mathrm{c}}(r, z, t)}{\partial t}+\bar{u}_{\mathrm{r}}(r, z, t) \frac{\partial T_{\mathrm{c}}(r, z, t)}{\partial r}+\right.$
$\left.+\bar{u}_{\mathrm{z}}(r, z, t) \frac{\partial T_{\mathrm{c}}(r, z, t)}{\partial t}\right]=h_{\mathrm{c}}(r, z, t) a_{\mathrm{ex}}^{\nu}\left[T_{\mathrm{w}}(r, z, t)-T_{\mathrm{c}}(r, z, t)\right]$.

Tube-wall heat balance:

$$
\begin{aligned}
\varrho_{\mathrm{w}} c_{\mathrm{pw}} \varepsilon_{\mathrm{w}}^{\cup} \frac{\partial T_{\mathrm{w}}(r, z, t)}{\partial t} & =U(r, z, t) a_{\mathrm{in}}^{v}\left[T_{\mathrm{f}}(r, z, t)-T_{\mathrm{w}}(r, z, t)\right]- \\
& -h_{\mathrm{c}}(r, z, t) a_{\mathrm{ex}}^{v}\left[T_{\mathrm{w}}(r, z, t)-T_{\mathrm{c}}(r, z, t)\right] .
\end{aligned}
$$

Tube-side heat balance:

$$
\begin{gathered}
a_{\mathrm{t}}\left[(1-\varepsilon) \varrho_{\mathrm{s}} c_{\mathrm{ps}}+\varepsilon \varrho_{\mathrm{f}} c_{\mathrm{pf}}\right] \frac{\partial T_{\mathrm{f}}(r, z, t)}{\partial t}+a_{\mathrm{t}} \varrho_{\mathrm{f}} c_{\mathrm{pf}} u_{\mathrm{s}} \times \\
\quad \times \frac{\partial T_{\mathrm{f}}(r, z, t)}{\partial z}=\varepsilon_{\mathrm{f}}^{u} \sum_{1}^{I}\left(-\Delta H_{\mathrm{Ri}}\right) r_{\mathrm{i}}\left(w, \varrho_{\mathrm{f}}, T_{\mathrm{f}}\right)- \\
U(r, z, t) a_{\mathrm{in}}^{v}\left[T_{\mathrm{f}}(r, z, t)-T_{\mathrm{w}}(r, z, t)\right] .
\end{gathered}
$$

Mass balance of reactants:

$\varepsilon \varrho_{\mathrm{f}} \frac{\partial w_{\mathrm{i}}(r, z, t)}{\partial t}+\varrho_{\mathrm{f}} u_{\mathrm{s}} \frac{\partial w_{\mathrm{j}}(r, z, t)}{\partial z}=\varepsilon M_{\mathrm{j}} \sum_{1}^{I} v_{\mathrm{ij}} r_{\mathrm{i}}\left(w, \varrho_{\mathrm{f}}, T_{\mathrm{f}}\right)$.

In order to account for gas density and pressure changes in the catalyst filled tubes, the above model has been completed with the following equations:

Ergun's equation:

$\frac{\partial p}{\partial z}=f_{1} u_{\mathrm{s}}+f_{2} u_{\mathrm{s}}^{2}$

Ideal gas law:

$e_{\mathrm{f}}=\frac{p(r, z, t)}{R T_{\mathrm{f}}(r, z, t)} \sum_{\mathrm{l}}^{J} \frac{M_{\mathrm{j}}}{w_{\mathrm{j}}(r, z, t)}$.

As can be seen from Eqs (8) - (11), several assumptions have been made in the development of the present model, namely:

- The tube-side process can be approximated by the onedimensional pseudo-homogeneous model with axial diffusion/conduction terms neglected.

- Axial conductivity in the tube wall is neglected. Heat capacity of the tube wall is, however, taken into consideration.

- In the reactor shell, the cylindrical symmetry of the coolant flow is preserved, i.e. coolant inlets/outlets are uniformly positioned along the shell (or central tube) circumference, so that there is no circumferential component of the coolant flow by-passing the tube bundle.

\subsection{Initial and Boundary Conditions for the Model}

The model described by Eqs (8) - (13) can be completed with the following initial conditions:

$t=0 \rightarrow\left\{\begin{array}{l}T_{\mathrm{c}}=T_{\mathrm{co}}(r, z) \\ T_{\mathrm{w}}=T_{\mathrm{wo}}(r, z) \\ T_{\mathrm{f}}=T_{\mathrm{fo}}(r, z) \\ w_{\mathrm{j}}=w_{\mathrm{jo}}(r, z) \\ p=p_{\mathrm{o}}(r, z)\end{array}\right.$

As far as the boundary conditions are concerned, their formulation for the tube-side variables is rather obvious:

$\left.\begin{array}{r}z=0 \\ 0<R\end{array}\right\} \rightarrow\left\{\begin{array}{l}T_{\mathrm{f}}=T_{\mathrm{f}, \text { in }}(t) \\ w_{\mathrm{j}}=w_{\mathrm{j}, \mathrm{in}}(t)\end{array}\right.$

However, the boundary conditions for coolant temperature largely depend both on reactor configuration and on the problem under investigation. In our case, it was assumed that the coolant temperature is

$T_{\mathrm{c}}=T_{\mathrm{c}, \mathrm{in}}(t)$ for $\quad r=R_{\mathrm{in}}$,

$0<z<H_{\mathrm{in}}$.

where $R_{\text {in }}$ is the radial position of coolant inlet (in practice $R_{\text {in }}$ is equal either to the radius of the reactor shell or to that of the central tube), while $H_{\text {in }}$ denotes the height of the coolant inlet.

On the other hand, assumption of a perfect insulation of the reactor shell and axial symmetry of coolant flow allows to set

$\frac{\partial T_{\mathrm{c}}}{\partial r}=0$ or $\frac{\partial T_{\mathrm{c}}}{\partial z}=0$

at all other boundaries, except for coolant inlets/outlets, as shown schematically in Fig. 1 for the case of reactor with diskand-doughnut baffles.

\subsection{Solution of the Model}

The tube-side balances of the presented model were spacediscretized by backward finite differences, while the shell-side was approximated by a network of corresponding two-dimensional CSTR's for which local coolant velocities $\bar{u}_{\mathrm{r}}$ and $\bar{u}_{\mathrm{z}}$ were determined, based on the earlier developed method for the calculation of coolant flow distribution in the intertubular space [4]. Typical distributions of radial and axial coolant flows, obtained by the above method, can be found elsewhere $[4,10]$.

When solving the model, the number of space grid points in both directions varied depending on the run but, on the average, the total number ranged between 800 and 1200 . In order to solve the resultant very large systems of ODE's 


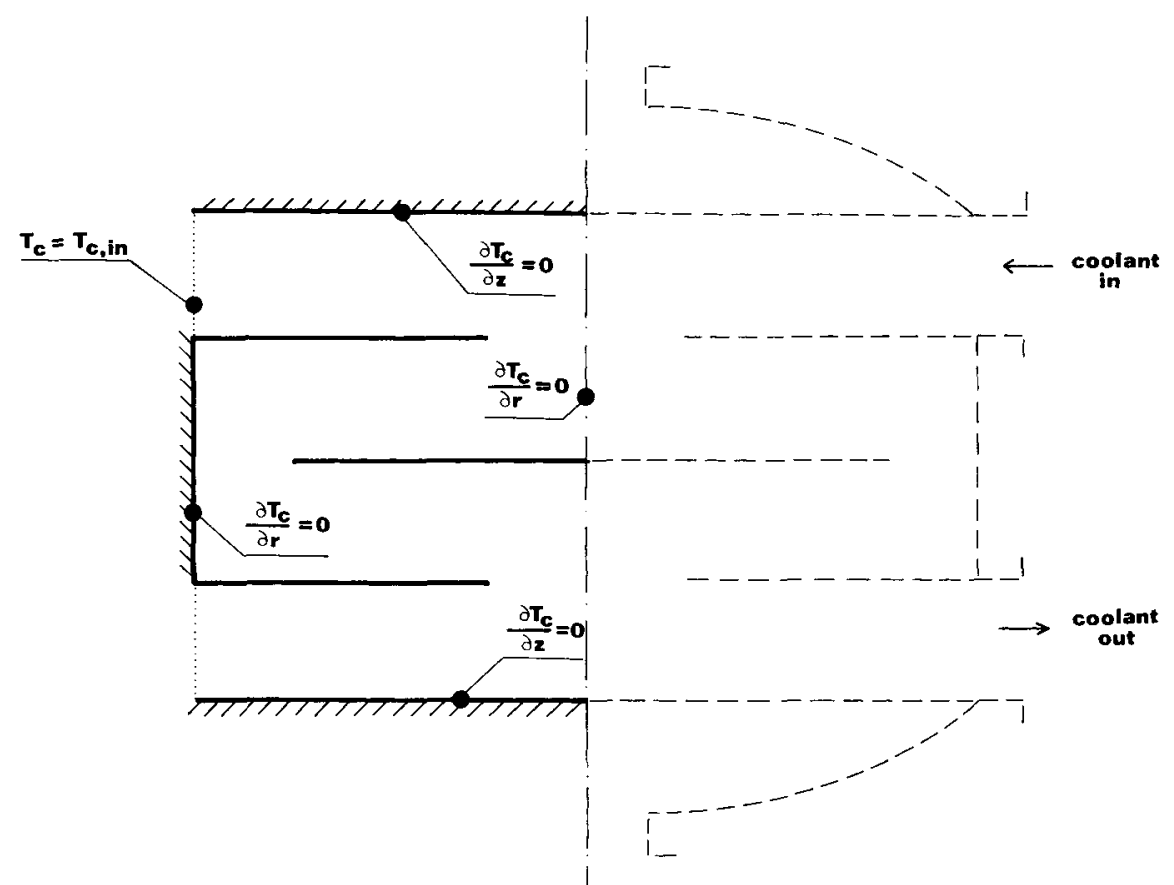

Fig. 1. Boundary conditions for shell-side heat balance.

(4000-8000), the LIMEX integrator, based on semi-implicit Euler's method [11, 12] and utilizing the AERE Harwell sparse matrix code [13], was used in this study.

\section{Analysis of Results}

The above dynamic model of the multitubular reactor was used for numerical simulation and comparative analysis of the dynamic behaviour of two basic alternatives of cocurrent industrial units, i.e. the crossflow reactor fitted with three diskand-doughnut baffles and the parallel flow reactor fitted with distributing plates. Both investigated units have the same basic geometrical parameters, namely:

$D=4.652 \mathrm{~m}$,

$N=12,144$ tubes,

$d=31.8 \times 1.5 \mathrm{~mm}$,

$t_{\mathrm{p}}=40 \mathrm{~mm}$,

$s=0.2 \mathrm{~mm}$,

$g=12 \mathrm{~mm}$,

$L=3.0 \mathrm{~m}$.

In both types of reactor, the coolant is fed circumferentially and its inlets are assumed to be uniformly distributed along the shell perimeter.

On the tube-side, a highly exothermic reaction of the type

$$
\begin{gathered}
\mathrm{A} \stackrel{k_{1}}{\rightarrow} \mathrm{B} \\
k_{3} \searrow_{\mathrm{C}} \swarrow_{k_{2}},
\end{gathered}
$$

resembling the oxidation of benzene, is assumed, with kinetic data of Naim [14]. The inlet values of operational variables at steady state (initial conditions) are as follows:

$$
\begin{aligned}
G & =0.86 \mathrm{~kg} / \mathrm{m}^{2} \mathrm{~s}, \\
w_{\mathrm{a}, \text { in }} & =0.031 \mathrm{~kg} / \mathrm{kg}, \\
T_{\mathrm{c}, \text { in }} & =703 \mathrm{~K}, \\
T_{\mathrm{w}, \text { in }} & =703 \mathrm{~K}, \\
T_{\mathrm{f}, \text { in }} & =703 \mathrm{~K}, \\
P_{\text {out }} & =1.5 \times 10^{5} \mathrm{~Pa} .
\end{aligned}
$$

The local heat transfer coefficients, both on tube and shell sides (in crossflow and in parallel flow) were calculated from correlations recommended in [3].

As a rule, the parallel flow reactor is more sensitive to various input disturbances in the operational variables. This especially applies to the tubes positioned further from the coolant inlet and subjected to unfavourable conditions of heat removal, due to coolant leakages through the tube-to-baffle clearances. Fig. 2 shows the time responses of reactant temperature to a step increase in inlet concentration by $5 \%$ of the initial value, in the reactor with parallel coolant flow for tubes positioned near the coolant inlet (reactor circumference) and on the opposite side of the tube bundle (reactor axis). Fig. 3 presents the corresponding situation in the reactor with three disk-and-doughnut baffles which appeared to be much less sensitive, regarding both the response amplitude and the positions of the catalytic tubes.

A similar situation can be observed in the case of a step decrease in the coolant flow rate by ca. $50 \%$. The reactor with parallel coolant flow responded strongly (Fig. 4) via significant increase of temperature in the fixed beds while, in the unit fitted with disk-and-doughnut baffles, there was practically no change in the temperature profiles (Fig. 5).

The observed behaviour is mainly due to the considerable differences between the crossflow and parallel flow heat transfer coefficients on the shell-side which, in some cases, may differ by as much as an order of magnitude. Local irregularities, 

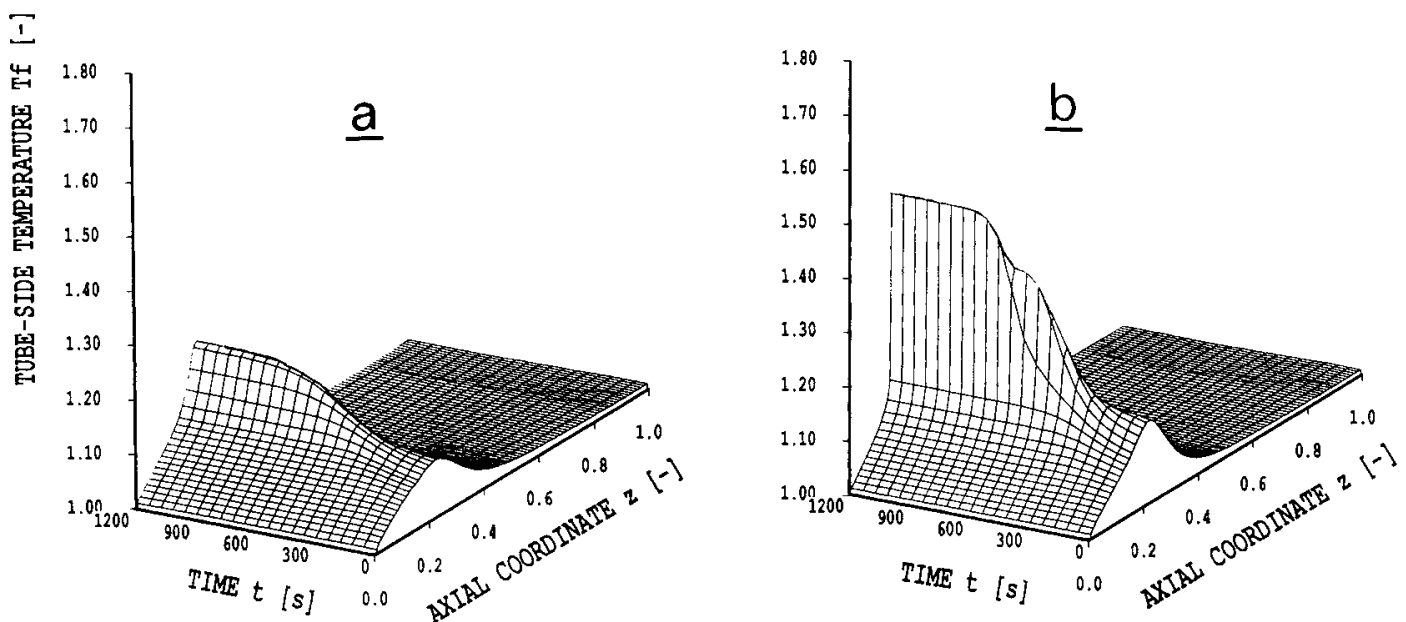

Fig. 2. Response of parallel flow reactor to step increase in reactant concentration. a) tube near coolant inlet (reactor circumference), b) tube on opposite of bundle (reactor axis).
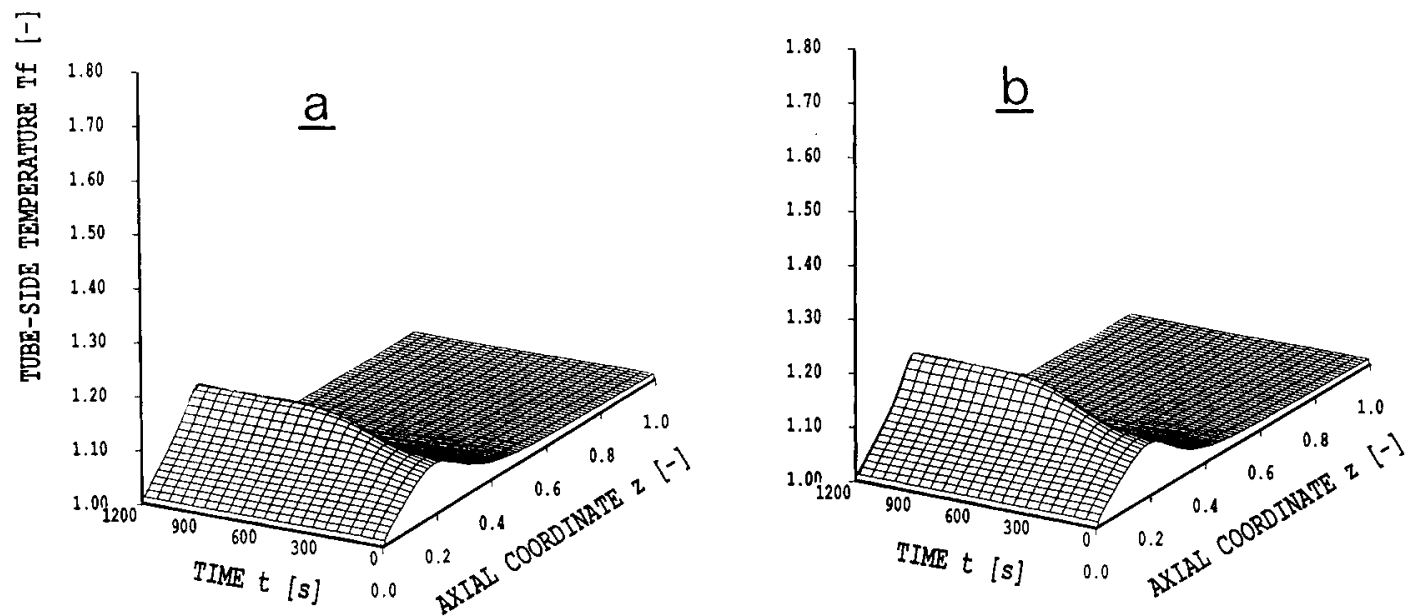

Fig. 3. Response of reactor with disk-and-doughnut baffles to step increase in reactant concentration. a) tube near coolant inlet (reactor circumference), b) tube on opposite side of bundle (reactor axis).
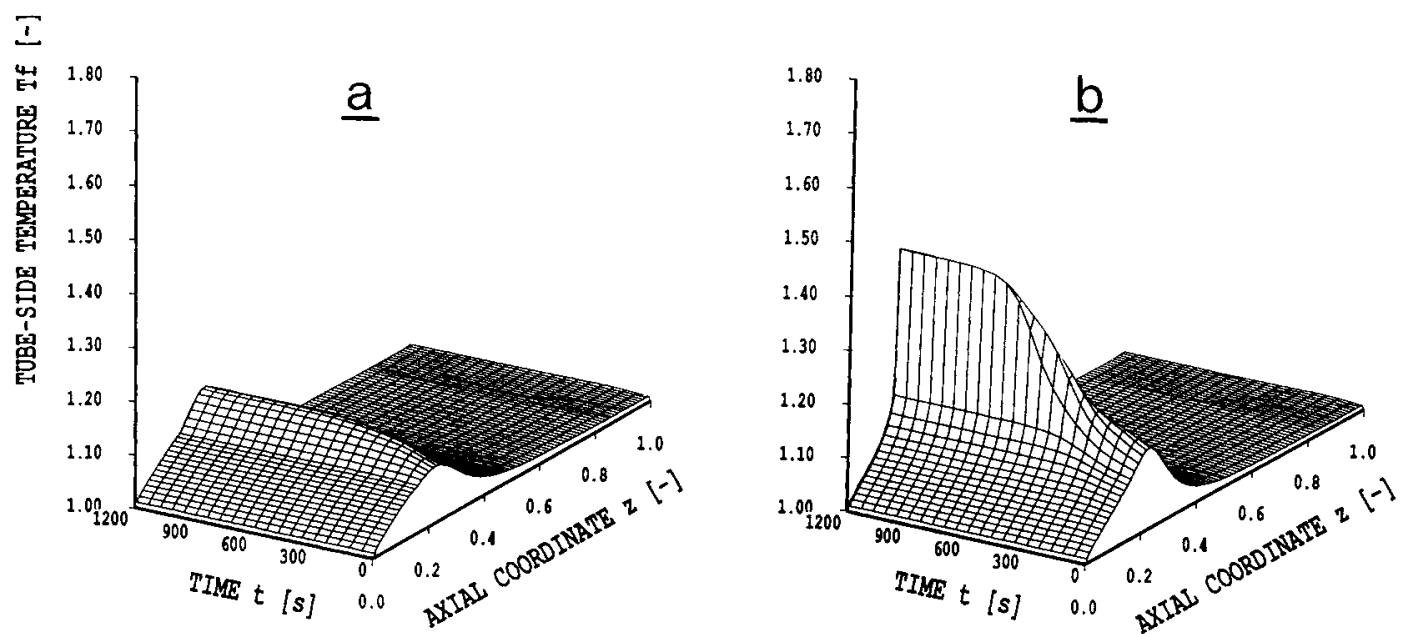

Fig. 4. Response of parallel flow reactor to step decrease in coolant tlow rate. a) tube near coolant inlet (reactor circumference), b) tube on opposite side of bundle (reactor axis). 

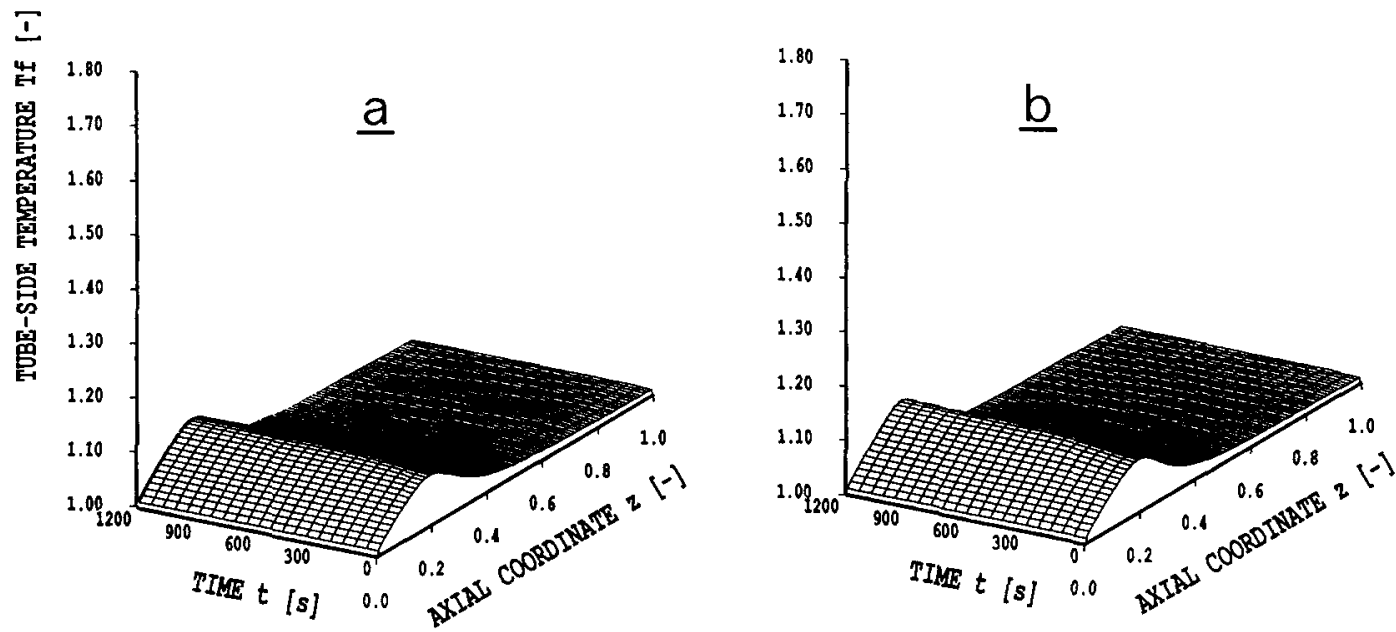

Fig. 5. Response of reactor with disk-and-doughnut baffles to step decrease in coolant flow rate. a) tube near coolant inlet (reactor circumference), b) tube on opposite side of bundle (reactor axis).

which can be seen in the initial steady-state profiles in Figs $2 a$ and $4 a$, correspond exactly to the axial position of the distributing plate, i.e. the location where the shell-side heat transfer coefficients changed their value from ca. 4000 to ca. $700 \mathrm{~W} / \mathrm{m}^{2} \mathrm{~K}$.

It is worth noting that, at very strong disturbances, especially in the tubes with poor heat removal, the density of the space grid may play an important role in obtaining reliable results from the simulation runs. This is illustrated by the example shown in Figs 6 and 7. Fig. 6 presents a false result of simulation of a response to a double-ramp increase in the inlet gas

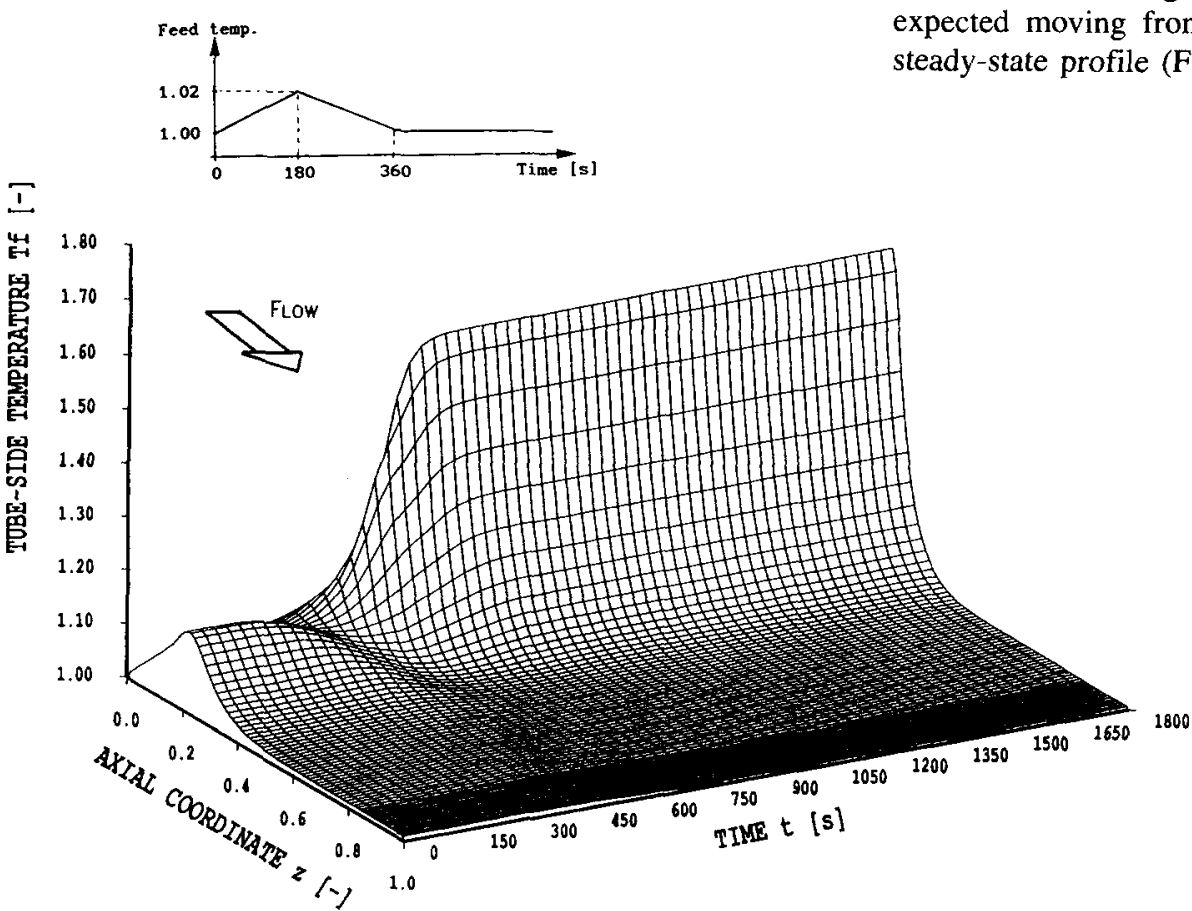

temperature with the amplitude of $20 \mathrm{~K}$, in the centrally positioned tubes of the parallel flow reactor. The simulation run was carried out with an equidistant grid of 80 points over a tube 3 metres long. The simulation shows a transition to an apparent upper steady state. However, multiple steady states are not possible with the initial value problem considered. The result is obviously an artefact, introduced by the coarse spatial discretization. Here, every spatial element of the considered tube behaves as a stirred tank in a cascade and the apparent multiplicity constitutes a well-known feature of a CSTR cascade.

Indeed, increase of grid density by a factor of 4 produced the expected moving front with the reconstruction of the initial steady-state profile (Fig. 7).

Fig. 6. False response in parallel flow unit to a double-ramp increase in gas temperature, due to insufficient density of axial grid. 

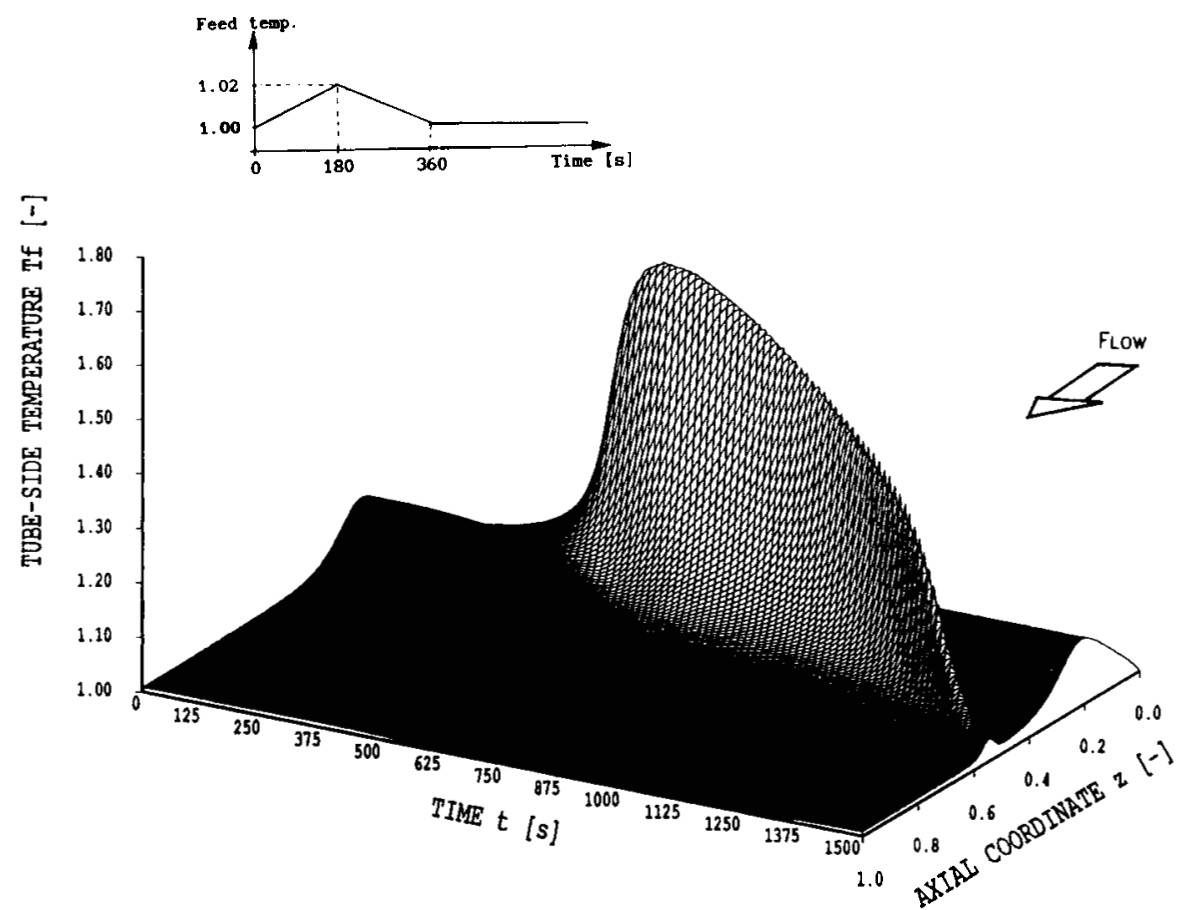

Fig. 7. Correct response for the case of Fig. 6, obtained by quadrupling the density of space grid.

Obviously, refining of the space grid is uneconomical from a computational viewpoint and for such cases other techniques, involving time-dependent regridding procedures, are recommended.

Several such procedures were proposed in [15] and their application to the problems presented in this study has produced quite promising results.

Fortunately, disturbances such as those shown in Figs 6 and 7 are not common in industrial practice on account of careful con-

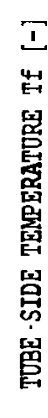

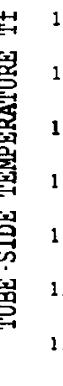

trol of the feed parameters. In addition, the incorporation of an inert entrance section into the tubes, acting as reactant preheater, allows to avoid such strong responses to the disturbances in gas temperature. This can be seen in Fig. 8 where the same disturbance as in Fig. 7 has been simulated assuming the presence of an inert packing upstream of the active catalyst bed.

\section{Conclusions}

The dynamic model of multitubular fixed-bed reactors proposed in this study showed potential differences in responses to various disturbances, depending on the geometrical configuration (type) of intertubular space. It has been established that parallel flow reactors show much more sensitive behaviour, especially in tubes far from the coolant inlet. This is attributed to the shell-side heat transfer coefficient which, in parallel flow, is many times lower than that in crossflow.

Fig. 8. Response to double-ramp disturbance of Figs 6 and 7, assuming an inert bed section at tube entrance 
In the case of very sensitive exothermic reactions, if the equidistant axial grid in model discretization is not sufficiently dense, false results may be obtained. Therefore, in such cases, the appropriate regridding procedures should be employed during simulation runs.

\section{Acknowledgements}

This study was carried out at the Institut fuer Chemische Verfahrenstechnik of Stuttgart University. Financial support by the Alexander von Humboldt Stiftung and the Volkswagen Stiftung is gratefully acknowledged.

Received: January 14, 1991 [CET 362]

\begin{tabular}{|c|c|c|}
\hline$t_{\mathrm{p}}$ & [m] & tube pitch \\
\hline$T_{\mathrm{c}}$ & {$[\mathrm{K}]$} & coolant temperature \\
\hline$T_{\mathrm{f}}$ & {$[\mathrm{K}]$} & gas temperature \\
\hline$T_{\mathrm{w}}$ & {$[\mathrm{K}]$} & tube-wall temperature \\
\hline$u_{\mathrm{r}}$ & {$[\mathrm{m} / \mathrm{s}]$} & coolant superficial velocity in radial direction \\
\hline$u_{\mathrm{s}}$ & {$[\mathrm{m} / \mathrm{s}]$} & superficial gas velocity \\
\hline$u_{z}$ & {$[\mathrm{~m} / \mathrm{s}]$} & coolant superficial velocity in axial direction \\
\hline$U$ & {$\left[\mathrm{~W} / \mathrm{m}^{2} \mathrm{~K}\right]$} & tube-side heat transfer coefficient \\
\hline$w_{\mathrm{j}}$ & {$[\mathrm{kg} / \mathrm{kg}]$} & mass fraction of $j$-th component \\
\hline s & {$[\mathrm{m}]$} & axial coordinate \\
\hline$\varepsilon$ & {$[-]$} & porosity of fixed bed \\
\hline$\nu_{\mathrm{ij}}$ & {$[-]$} & $\begin{array}{l}\text { stoichiometric coefficient of } j \text {-th component in } \\
i \text {-th reaction }\end{array}$ \\
\hline$\varrho_{c}$ & {$\left[\mathrm{~kg} / \mathrm{m}^{3}\right]$} & coolant density \\
\hline$\varrho_{\mathrm{f}}$ & {$\left[\mathrm{kg} / \mathrm{m}^{3}\right]$} & gas phase density \\
\hline$\varrho_{s}$ & {$\left[\mathrm{~kg} / \mathrm{m}^{3}\right]$} & solid phase density \\
\hline & {$\left[\mathrm{kg} / \mathrm{m}^{3}\right]$} & tube-wall density \\
\hline
\end{tabular}

\section{References}

[1] Eigenberger, G., Ruppel, W., Chem.-Ing.-Tech. 57 (1985) No. 3, pp. $181-190$

[2] Eigenberger, G., The use of computer models in reactor design and their future application in design and operation, 7th Int. Symp. Large Chemical Plants, Bruges 1988.

[3] Stankiewicz, A., Chem. Eng Technol. 12 (1989) No. 2, pp. $113-130$.

[4] Stankiewicz, A., Chem. Eng Technol. 12 (1989) No. 3, pp $170-175$.

[5] Gilles, E.D., Holl, P., Marquardt, W., Chem.-Ing.-Tech. 58 (1986) No. 4 , pp. $268-278$

[6] Holl, P., Marquardt, W., Gilles, E.D., Comput. Chem. Eng 12 (1988) No. 5, pp. $421-426$

[7] Adderley, C.I., Thesis, Univ. Leeds 1973.

[8] Dunbobbin, B.R., Thesis, Univ. Leeds 1976.

[9] Biscaia, E.Ch., jr., Thesis, Univ. Fed. Rio de Janeiro 1980.

[10] Stankiewicz, A., Thesis, Ind. Chem. Res. Inst., Warszawa 1985.

[11] Deuflhard, P., Hairer, E., Zugck, J., Numer. Math. 51 (1987) pp. $501-516$.

[12] Deuflhard, P., Nowak, U., Prog. Sci. Comput. 7(1987) pp. 37-50.

[13] Duff, I.S., Reid, J.K., ACM Trans. Math. Software 5 (1979) No. 1 pp. $18-35$.

[14] Naim, H., Thesis, Univ. Leeds 1974.

[15] Rettinger, H., Studienarbeit, Univ. Stuttgart 1989. 